\title{
Diameter distribution model development of tropical hybrid Eucalyptus clonal plantations in Sumatera, Indonesia: A comparison of estimation methods
}

\author{
Joni Waldy ${ }^{1 *}$, John A. Kershaw Jr², Aaron Weiskittel ${ }^{3}$ and Mark J. Ducey ${ }^{4}$ \\ ${ }^{1}$ Faculty of Forestry and Environmental Management, University of New Brunswick, 28 Dineen Dr. Fredericton, NB E3B 5A3, Canada/ \\ Forest Planning Division, Asia Pacific Resources International Holdings Limited (APRIL), Indonesia \\ ${ }^{2}$ Faculty of Forestry and Environmental Management, University of New Brunswick, 28 Dineen Dr. Fredericton, NB E3B 5A3, Canada \\ ${ }^{3}$ Center for Research on Sustainable Forests, University of Maine, Orono, ME 04469, USA \\ ${ }^{4}$ Department of Natural Resources and the Environment, University of New Hampshire, 114 James Hall, 56 College Road, Durham, NH 03824, USA
}

*Corresponding author: jwaldy@unb.ca

(Received for publication 2 March 2021; accepted in revised form 22 November 2021)

\begin{abstract}
Background: Effective forest management and planning often requires information about the distribution of volume by size and product classes. Size-class models describe the diameter distribution and provide information by diameter class, such as the number of trees, basal area, and volume per unit of area. A successful diameterdistribution model requires high flexibility yet robust prediction of its parameters. To our knowledge, there are no studies regarding diameter distribution models for Eucalyptus hybrids in Indonesia. Therefore, the aim of this study was to compare different recovery methods for predicting parameters of the 3-parameter Weibull distribution for characterising diameter distributions of Eucalyptus hybrid clone plantations, on Sumatera Island of Indonesia.

Methods: The parameter recovery approach was proposed to be compatible with stand-average growth and yield models developed based on the same data. Three approaches where compared: moment-based recovery, percentilebased prediction and hybrid methods. The ultimate goal was to recover Weibull parameters from future stand attributes, which were predicted from current stand attributes using regression models.

Results: In this study, the moment method was found to give the overall lowest mean error-index and KolmogorovSmirnov (KS) statistic, followed by the hybrid and percentile methods. The moment-based method better fit long tails on both sides of the distribution and exhibited slightly greater flexibility in describing plots with larger variance than the other methods.

Conclusions: The Weibull approach appeared relatively robust in determining diameter distributions of Eucalyptus hybrid clone plantation in Indonesia, yet some refinements may be necessary to characterize more complex distributions.
\end{abstract}

Keywords: 3-parameter Weibull; parameter recovery method; moment-based estimates; percentile estimates; hybrid parameter estimates; Indonesia, Eucalyptus hybrids

\section{Introduction}

Effective forest management and planning often requires information about the distribution of volume by size and product classes (Burkhart \& Tomé 2012). Size-class and individual-tree models are required for predicting distributions of multiple products (Weiskittel et al. 2011), since they provide detailed yield estimates by size (De Miguel et al. 2010). Size-class models predict diameter distributions and provide estimates of forest attributes (such as the number of trees, basal area, and volume per unit area) by diameter class (Poudel \& Cao 2013). 
The concept of diameter distributions is not new to forestry literature (de Liocourt 1898). Several probability density functions are used to describe the structure of forest stands, including Weibull distributions (Bailey \& Dell 1973). The Weibull distribution is one of the most widely used diameter distribution models (Burkhart \& Tomé 2012) and one of the best-performing models among other distributions (Eisfeld et al. 2005).

The Weibull distribution is a flexible distribution function capable of fitting a variety of distribution shapes (Poudel \& Cao 2013). It has a lower bound and calculations of proportions of trees across diameter classes is straightforward and does not require numeric integration (Cao 2012). In addition, the parameters of the Weibull distribution are generally well correlated with several stand-level attributes (Bailey \& Dell 1973), such as dominant height, quadratic mean diameter, and mean diameter (Sghaier et al. 2016). Because of its flexibility, the Weibull distribution is applicable to many different species and forest structures from pure, single cohort, even-aged stands to multispecies, multicohort, uneven-aged stands (Mattney \& Sullivan 1982; Hyink \& Moser 1983; Knowe et al. 1994; Knowe \& Stein 1995; Siipilehto 1999; Cao 2004; Newton et al. 2005).

The three-parameter Weibull distribution function is commonly used to quantify tree diameter distributions because of: its flexibility in fitting a variety of shapes and degrees of skewness; the relative simplicity of estimating its parameters; and the cumulative distribution has a closed-form solution (Bailey \& Dell 1973; Bowling et al. 1989; Little 1983; Matney \& Sullivan 1982; Rennolls et al. 1985; Schreuder \& Swank 1974; Zarnoch et al. 1991). The probability density function (PDF) for the threeparameter Weibull distribution is specified by:

$$
\begin{aligned}
f(x)= & \frac{\gamma}{\beta}\left(\frac{x-\alpha}{\beta}\right)^{\gamma-1} \exp \left[-\left(\frac{x-\alpha}{\beta}\right)^{\gamma}\right] \quad(\alpha \leq x<\infty) \\
= & 0, \text { otherwise }
\end{aligned}
$$

Integration yields a closed-form cumulative distribution function (CDF):

$$
F(X \leq x)=1-\exp \left[-\left(\frac{x-\alpha}{\beta}\right)^{\gamma}\right] \quad(\alpha \leq x<\infty)
$$

The parameter $\alpha$ is referred to as the location parameter and defines the minimum value of the distribution, $\beta$ is the scale parameter, $\gamma$ is the shape parameter and $x$ is diameter at breast height (Clutter et al. 1983). The $\beta$ and $\gamma$ parameters must be positive, while $\alpha$ mathematically can be positive, zero, or negative (provided $x-\alpha \geq 0$ ). For diameter distribution applications $\geq 0$.

For shape $(\gamma)$ parameters less than 1, the Weibull distribution assumes a classic inverse J-shape distribution typically found in uneven-aged stands, while when $\gamma$ equals 1 , the negative exponential distribution results. Mound shape curves typical of even-aged stands are produced for $\gamma$ greater than 1 (Burkhart \& Tomé 2012). When $\gamma$ is equal 3.6, the Weibull distribution is symmetrical, similar to a normal distribution shape. Right-skewed curves are defined for $\gamma$ less than 3.6 and left-skewed curves for $\gamma$ greater than 3.6. As $\gamma$ approaches infinity, the distribution approaches a spike over a single point (Burkhart \& Tomé 2012). The location parameter often is assumed known in many cases, so it is logical to set this parameter to the smallest value or the lower limit of diameter measurement (Kershaw et al. 2016).

Parameter estimates based on maximum likelihood methods for the Weibull distribution requires individual tree data (Bolker 2008). Maximum likelihood estimation has several desirable statistical properties, such as consistency and asymptotic normality (Bury 1999; Royle \& Dozario 2008), and provides better estimates compared to other methods (Zhou \& McTague 1996). However, it requires more computational resources (Cao \& McCarty 2006) and precise individual tree measurements. In most forestry applications, diameter distributions are generally predicted from characteristics measured in a stand of interest. Hyink and Moser (1983) presented a generalized framework for estimating diameter distributions using parameter prediction methods (PPM) and parameter recovery methods (PRM). In the PPM approach, the future parameters of the distribution model are directly predicted from the current parameters and other information about the stand such as density, basal area and volume. (Kershaw et al. 2016). The PPM uses the location $(\alpha)$, scale $(\beta)$, and shape $(\gamma)$ parameters as the dependent variables, which have been previously estimated using maximum likelihood methods (Cao 2004). In the PRM approach, future values of stand parameters are directly predicted, and the parameters of the diameter distribution are derived from the stand parameters (Hyink \& Moser 1983; Kershaw et al. 2016).

The parameter prediction approach using the Weibull distribution has been applied to many different species and forest types: pine (Pinus taeda L. and Pinus echinate Mill.) plantations (Smalley \& Bailey1974 a,b); slash pine (Pinus elliottii) plantations (Dell et al. 1979); longleaf pine (Pinus palustris Mill.) plantations (Leduc et al. 2001); loblolly pine (Pinus taeda) plantations (Clutter et al. 1984; Feduccia et al. 1979; Smalley \& Bailey 1974a); natural slash pine (Pinus elliotti) stands (Schreuder et al. 1979); mixed stands of western hemlock and Douglasfir (Pseudotsuga menziesii and Tsuga heterophylla) (Little 1983); Sitka spruce (Picea sitchensis) plantations (Rennolls et al. 1985); and Norway spruce (Picea abies) plantations (Kilkki \& Päivinen 1986; Kilkki et al. 1989; Siipilehto 1999) and many others (Vanclay 1994; Weiskittel et al. 2011). While parameter predictions can be easily derived from regression equations fit to precisely estimated diameter distributions, these models often produce poorer parameter predictions, low $\mathrm{R}^{2}$ values for $\alpha$ and $\gamma$ parameters; and are not responsive to silvicultural treatments (Hyink \& Moser 1983). Because PPM does not work very well in many cases, this approach was not considered in this study.

According to Siipilehto and Mehtätalo (2013), there are two main options for PRM approaches: moment-based and percentile-based estimation. The 
PRM moment-based approach solves for the Weibull parameters typically using the moments of the diameter distribution that are estimated from regression equations using a variety of stand characteristics (Bowling et al. 1989; Hyink \& Moser 1983; Lindsay et al. 1996; Matney \& Sullivan 1982; Newton et al. 2004; Strub \& Burkhart 1975) or from stand-level models predicting future stand conditions (Clutter et al. 1983; Waldy et al. 2021). The percentile-based method predicts the Weibull parameters using percentiles of the diameter distribution that also can be estimated from stand characteristics (Bailey et al. 1989; Brooks et al. 1992; Lohrey \& Bailey 1976; Knowe 1992; Magnussen 1986; McTague \& Bailey 1987). Other methods, such as a hybrid approach (McTague \& Bailey 1987), cumulative distribution function regressions (CDFR; Cao 2004), and modified CDFRs (Poudel \& Cao 2013) also have been proposed.

A successful diameter-distribution model requires robust predictions of its parameters. The PRM approach was proposed because its estimates were compatible with stand-average growth and yield models developed from the underlying diameter distribution data (Hyink \& Moser 1983). Other methods were proposed because of the nature of the underlying data and/or the objectives of the study. In this study, the overall objective of this analysis was to evaluate different parameter recovery methods for predicting parameters of the Weibull PDF for characterising diameter distributions of Eucalyptus hybrid clone plantations in Sumatera, Indonesia. The specific objectives were to: (1) compare moment-based, percentile-based and hybrid methods; (2) determine the best approach for robust estimation of diameter distributions across a full range of current and future predicted stand conditions; and ( 3 ) based on observed performance, predict moments and/or percentiles from stand and site characteristics using nonlinear regression analyses.

\section{Methods}

\section{Study site}

This study was conducted in Sector Teso East of PT. Riau Andalan Pulp and Paper, a member of Asia Pacific Resources International Holding Limited (APRIL) Group and used inventory plot data from Eucalyptus hybrid plantations. Teso East is 19,600 ha in size and is located in the central region of Sumatera Island, Riau Province, Indonesia in the Kampar and Kuantan Singingi regencies between $101^{\circ} 18^{\prime} \mathrm{E}$ and $101^{\circ} 32^{\prime} \mathrm{E}$, and $00^{\circ} 09^{\prime} \mathrm{N}$ and $00^{\circ} 03^{\prime} \mathrm{N}$ (Figure 1 ). The region is characterised by a wet tropical climate with average rainfall ranging from 2000$3000 \mathrm{~mm}$ per year, and the average rainy days is around 160 days per year. The annual average temperature is $27.6^{\circ} \mathrm{C}$ with an average minimum of $21.8^{\circ} \mathrm{C}$ and an average maximum of $35^{\circ} \mathrm{C}$.

Until now, Estate Teso East has had its fifth rotation. The first rotation was planted with Acacia mangium in 1995 and then Eucalyptus sp. was planted on a large scale starting in 2010. Based on the soil characteristics, this study location was dominated by soil horizon B (topsoil) and C (parent material). This plantation area is relatively flat with slopes ranging from $0-15 \%$ and low elevation ranging from 30-90 metres above sea level.

\section{Data collection}

In APRIL plantations, the plot layout used systematic sampling with random starting points. Initial sampling intensity was $1 \%$ of total stand area (one plot represents 4 ha area) with an additional 2-5\% sampling intensity for a pre-harvest inventory (one year before harvest). Plots were circular with a radius of $11.28 \mathrm{~m}$ (0.04 ha). First measurements were made at six months after planting and regularly continued at twelve-month intervals until harvesting. $d b h$ was measured beginning at 18 months. All live trees with $d b h$ of $1.0 \mathrm{~cm}$ and greater on each

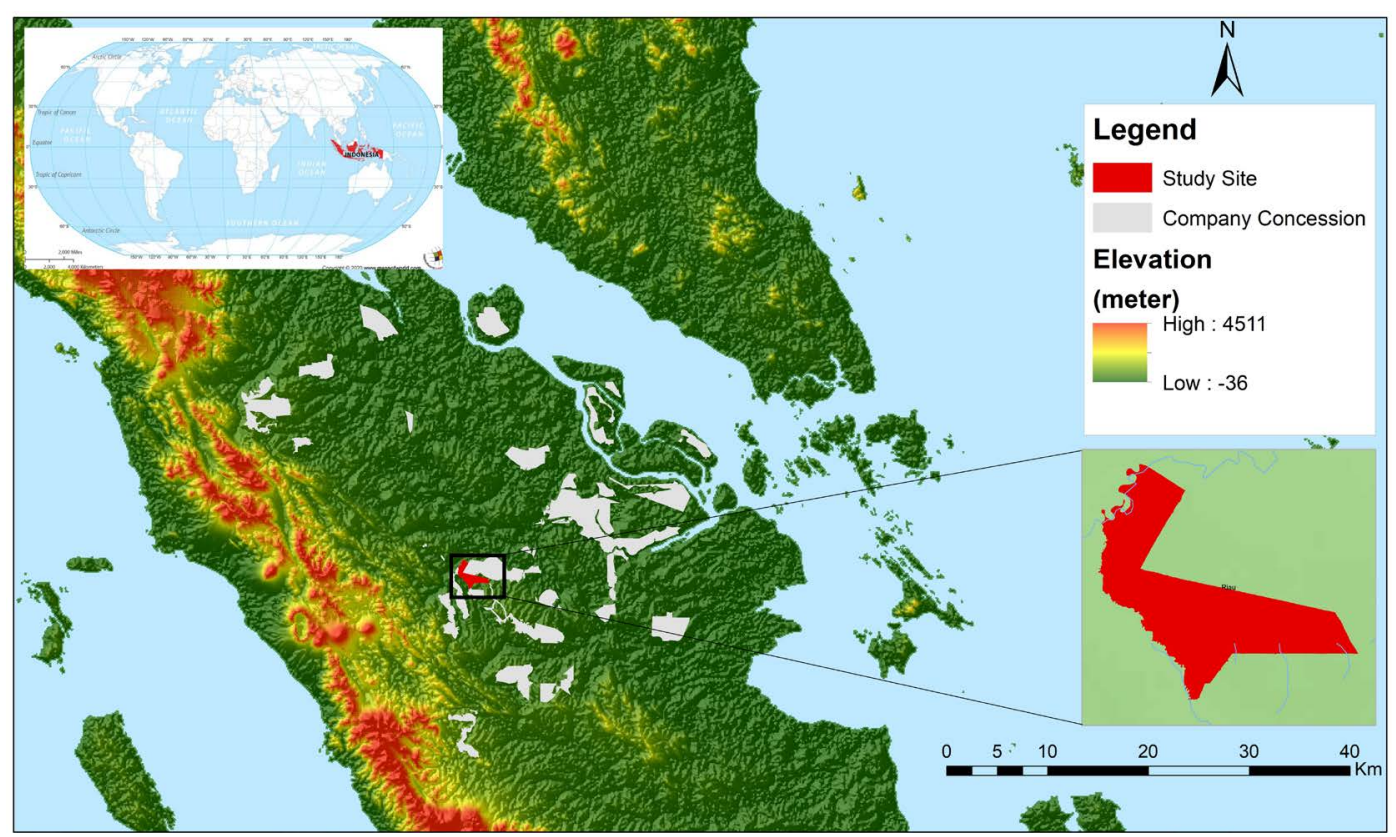

FIGURE 1: Location of the study area in the Sector Teso East, central region of Sumatera 
TABLE 1: Summarised stand attributes and their increment for the inventory plots $(\mathrm{n}=2808)$ used for modeling $(A=$ age; $\mathrm{HT}=$ top height; $\mathrm{BA}=$ basal area; $\mathrm{SD}=$ stand density; $\mathrm{DQ}=$ quadratic mean diameter; and $\mathrm{VOL}=$ stand volume).

\begin{tabular}{|c|c|c|c|c|c|c|c|c|}
\hline \multirow{2}{*}{ Stand attributes } & \multicolumn{4}{|c|}{$\begin{array}{c}\text { Clone A } \\
(n=2476)\end{array}$} & \multicolumn{4}{|c|}{$\begin{array}{c}\text { Clone B } \\
(n=332)\end{array}$} \\
\hline & Mean & Min & Max & Stdev & Mean & Min & Max & Stdev \\
\hline $\mathrm{A}$ (month) & 34.3 & 12 & 63.6 & 14.4 & 29.1 & 18 & 42 & 9.6 \\
\hline HT (m) & 17.3 & 5.8 & 30 & 5.7 & 18 & 10.6 & 27.7 & 4.4 \\
\hline $\mathrm{BA}\left(\mathrm{m}^{2} h \mathrm{a}^{-1}\right)$ & 12.4 & 1.8 & 26.9 & 5.2 & 14.2 & 3.9 & 22.9 & 3.8 \\
\hline SD $\left(\right.$ trees $\left.\cdot h^{-1}\right)$ & 1,536 & 175 & 2,101 & 209 & 1,569 & 450 & 1,851 & 203 \\
\hline $\mathrm{DQ}(\mathrm{cm})$ & 9.7 & 3.4 & 18.5 & 2.5 & 10.6 & 7.8 & 14.5 & 1.4 \\
\hline $\operatorname{VOL}\left(\mathrm{m}^{3} \mathrm{ha}^{-1}\right)$ & 73 & 0.05 & 234.4 & 53.37 & 85.71 & 14.69 & 189.8 & 42.63 \\
\hline
\end{tabular}

plot were measured using a diameter tape at 1.3 metres above the ground as measured from the uphill side of the stem. Each tree was assigned a status (live or dead), and assessed for wind damage, pests, and diseases.

This study only used the most recently established eucalyptus clone stands that were planted 2013 to 2016 with an initial spacing of $3 \times 2$ m (1667 trees per ha) and had at least three consecutive measurements. There are 2808 measurements in this study, where clone A and B accounted 2,476 and 332 plots, respectively. Table 1 summarises stand attributes and their associated increments by clone. In comparison to clone A, clone B is recently developed by the APRIL Group concession. The maximum age of existing inventory data for clone B is 42 months. Because of its promising growth (Table 1), it was important to include this clone in the modeling conducted in this study.

\section{Maximum likelihood estimation (MLE)}

Weibull parameters were estimated using the individual tree $d b h$ measurements from each plot at each measurement period using maximum likelihood estimation (MLE) methods (Johnson et al. 1995; Casella \& Berger 2001). The location parameter $(\alpha)$ was set to 1 $\mathrm{cm}$ in this study (minimum $\mathrm{dbh}$ measured), and the MLE estimates of the scale $(\beta)$ and shape $(\gamma)$ parameters were used as reference distributions to compare with the recovered parameter estimates. The likelihood function of the Weibull PDF (Eq. 1):

$$
L\left(x_{1}, \ldots, x_{n} ; \beta, \gamma\right)=\prod_{i=1}^{n} \frac{\gamma}{\beta}\left(\frac{x}{\beta}\right)^{\gamma-1} \exp \left(-\left(\frac{D}{\beta}\right)^{\gamma}\right)
$$

MLEs where obtained by minimising the negative of the logarithm of the likelihood function.

\section{Moment-based parameter recovery}

In moment-based parameter recovery, regression equations, as a function of mean top height, stand density, age, or relative density, are used to predict the arithmetic mean diameter ( $\bar{D}$, the first moment) and the quadratic mean diameter (DQ, the square root of the second moment). As with the MLE estimates, we set $\alpha=1$, our minimum measured $\mathrm{dbh}$. Weibull parameters were then recovered from the arithmetic mean diameter $(\bar{D})$ and quadratic mean diameter (DQ) using (Burkhart \& Tomé 2012):

$$
\beta=\frac{(\hat{D}-\alpha)}{\Gamma_{1}}
$$

$$
\widehat{D Q}^{2}-\alpha^{2} 2 \alpha \widehat{\bar{D}}-\beta^{2} \Gamma_{2}=0
$$

where $\widehat{D Q}$ was predicted $\mathrm{DQ}, \bar{D}$ was predicted $\bar{D}$, $\Gamma_{i}=\Gamma\left(1+\frac{i}{\gamma}\right)$ and $\alpha, \beta$, and $\gamma$ were recovered Weibull parameters. Eqs. 4 and 5 were numerically solved to recover the parameters using the algorithms developed by Kershaw and Maguire (1995).

\section{Percentile-based parameter recovery}

Percentile estimation of the Weibull parameters are relatively easy to obtain given the closed form solution of the cumulative distribution and the geometric interpretation of the distribution parameters (Zarnoch \& Dell 1985). Similar to the moment estimates, the percentile estimates are functions of the distribution parameters and are often highly correlated with forest stand characteristics (Borders et al. 1987; Knowe 1992; Knowe et al. 1992). If three sample percentiles are known, each can be equated to its corresponding Weibull cumulative distribution function value and the three equations can be solved iteratively for estimates of $\alpha, \beta$, and $\gamma$ (Burkhart \& Tomé 2012). If the location parameter is assumed known, then only two percentiles are required to estimate $\beta$ and $\gamma$.

Given the Weibull cumulative distribution function (Equation 2), and letting $\hat{D}_{p}$ represent the estimated $p^{\text {th }}$ percentile value of diameter in the sample, then: 


$$
p=1-\exp \left\{-\left[\frac{\left(\widehat{D}_{p}-\alpha\right)}{\beta}\right]^{\gamma}\right\}
$$

Solving Eq.6 for $\hat{D}_{p}$ yields:

$$
\widehat{D}_{p}=\alpha+\beta[-\ln (1-p)]^{\frac{1}{\gamma}}
$$

The scale parameter, $\beta$, is given by:

$$
\beta=\frac{\widehat{D}_{p}-\alpha}{[-\ln (1-p)]^{\frac{1}{\gamma}}}
$$

Given two percentiles $p_{1}$ and $p_{2}$ where $p_{1}<p_{2}, \gamma$ is estimated using:

$$
\gamma=\frac{\ln \left(\frac{\ln \left(1-p_{2}\right)}{\ln \left(1-p_{1}\right)}\right)}{\ln \left(\widehat{D}_{p_{2}}-\alpha\right)-\ln \left(\widehat{D}_{p_{1}}-\alpha\right)}
$$

Theoretically, any two percentiles can be used; however, Bailey et al. (1989) found best performance resulted when percentiles represented a broader proportion of the distribution. In this study, we used the $25^{\text {th }}$ and $99^{\text {th }}$ diameter percentiles to recover parameters $\beta$ and $\gamma$ of the Weibull distribution.

\section{Hybrid parameter recovery methods}

Moments and percentiles are combined in the hybrid approach (Bailey et al. 1989; Brooks et al. 1992; Knowe et al. 2005; Lee \& Coble 2006; Coble \& Lee 2008; and Jiang \& Brooks 2009). As in the other approaches, the location parameter was expected to be known (i.e., $\alpha=$ 1 ), and the $\beta$ and $\gamma$ parameters were recovered from a moment estimate and two percentile estimates using (Bailey et al. 1989):

$$
\begin{aligned}
& \beta=-\alpha \frac{\Gamma_{1}}{\Gamma_{2}}+\left[\left(\frac{\alpha}{\Gamma_{2}}\right)^{2}\left(\Gamma_{1}^{2}-\Gamma_{2}\right)+\frac{\widehat{D Q}^{2}}{\Gamma_{2}}\right]^{0.5} \\
& \gamma=\frac{\ln \left(\frac{\ln \left(1-p_{2}\right)}{\ln \left(1-p_{1}\right)}\right)}{\ln \left(\widehat{D}_{p_{2}}-\alpha\right)-\ln \left(\widehat{D}_{p_{1}}-\alpha\right)}
\end{aligned}
$$

Here we used estimates of DQ, $25^{\text {th }}$ and $99^{\text {th }}$ diameter percentiles to estimate $\beta$ and $\gamma$.

\section{Moment and percentile estimation}

The quadratic mean diameter, arithmetic mean diameter, and the percentiles were calculated for each plot and measurement period using the individual tree $d b h$ data. Several regression equation forms were used to predict the diameter moments or percentiles (e.g., Matney \& Farrar 1992; Baldwin \& Feduccia 1987; Cao 2004) based on stand characteristic. In this study, the logistic equation was used to predict arithmetic mean diameter $(\bar{D})$ and a modified general form of the regression equation from Cao (2004) to predict diameter percentiles with additional DQ variables to ensure compatibility with stand-level models (Waldy et al. 2021).

DQ was estimated using the relationship of basal area and stand density. In Waldy et al. (2021), the stand density model from Clutter et al. (1983) and basal area model derived from the Schumacher polymorphic equation were the best fit models based on several models evaluated, for projecting future attributes to any point in time. These time-based models gave DQ estimates with $\mathrm{rMSE}=0.72 \mathrm{~cm}$ and explained $85 \%$ of the variability (Waldy et al. 2021).

Arithmetic mean diameter $(\bar{D})$ was estimated using a logistic equation and the estimated DQ:

$$
\bar{D}=D Q\left(\frac{\exp \left(b_{0}+b_{1} R D+b_{2} \ln H T+b_{3} / A G E\right)}{1+\exp \left(b_{0}+b_{1} R D+b_{2} \ln H T+b_{3} / A G E\right)}\right)+\epsilon
$$

Finally, percentiles were estimated using:

$D_{i}=\exp \left[b_{0}+D Q\left(b_{1} R D+b_{2} \ln H T+b_{3} / A G E\right)\right]+\epsilon_{i}$

where $\bar{D}$ was arithmetic mean diameter $(\mathrm{cm}) ; D_{\mathrm{i}}$ was the $i^{\text {th }}$ diameter percentile $(\mathrm{cm})$; DQ was the quadratic mean diameter $(\mathrm{cm})$; RD was a relative density measure defined as the ratio of actual density to the maximum density attainable in a stand with the same mean tree size; HT was the top height (m); AGE was stand age (months); $b_{i}$ were regression parameters and $\epsilon$ was a random error term. Equation (12) assured that DQ $>\bar{D}$ because the logistic component,

$$
\frac{\exp \left(b_{0}+\cdots+b_{3} / A G E\right)}{1+\exp \left(b_{0}+\cdots+b_{3} / A G E\right)}<1 \text {, and } \exp (x)>0 \text {. }
$$

Fitted Eqs. 12 and 13 were used to predict each plot $\times$ measurement period moments.

Nonlinear regression was used to fit Eqs 12 and 13 and appropriate goodness of fit criteria were used to evaluate the moment and percentiles estimates. We then included clone and site class as random effects into the regression equations and nonlinear mixed effects methods (Pinheiro \& Bates 2000) were used estimate fixed and random effects for each model. A likelihood ratio test used to assess significance of random effects (Weiskittel et al. 2011).

\section{Model evaluation}

The Kolmogorov-Smirnov (KS) statistic (Massey 1951) and an error-index (EI; Reynolds et al. 1988) were computed for each method to evaluate the three prediction methods. Using a significance level of $5 \%$, the KS test was used to compare the estimated cumulative frequency and the observed frequency. The method producing the lowest average KS statistics and errorindex values was considered the best method. All estimation and analyses were carried out using the $\mathrm{R}$ statistical language (R Core Team 2020). 


\section{Results \\ Moment and percentile prediction models}

Using nonlinear least square analysis, all coefficients for Equation 12 and 13 to predict arithmetic mean diameter and diameter percentiles were significant $(\mathrm{p}<0.05)$. Consequently, all parameters associated with stand characteristics (DQ, RD, HT, and AGE) were included for mixed-effect analysis that involved clone and site class within clone as random effects (Table 2). Based on the likelihood ratio test, the best random-effects models included all coefficients as random effects of clone and site class within the clone (Table 2). Parameter estimates and their associated standard errors (in parentheses), random effects standard deviations, and goodness-of-fit statistics for the arithmetic mean diameter, $25^{\text {th }}$ and $99^{\text {th }}$ diameter percentiles are shown in Table 2. The full model with fixed and random effects accounted for 99\%, 77\% and $93 \%$ of the variation for $\bar{D}, D_{25}$ and $D_{99}$ prediction models, respectively (Table 2). The $D_{25}$ percentile model had the lowest performance compared with the $\bar{D}$ and $D_{99}$ models. Differences between clones were greater than differences across sites within clones for almost all modelling parameters, except $b_{1}$ and $b_{2}$ associated with the $D_{99}$ model (Table 2). Coefficient estimates (fixed + random effects) by clone and site classes for all prediction models are shown in Table 3.

\section{Characteristics of Maximum Likelihood Estimates}

The estimated Weibull scale parameters, $\beta$, based on the MLE method ranged from 3.95 to 15.11 and the shape parameters, $\gamma$, ranged from 1.68 to 11.50 (Table 4). Based on the K-S test, estimated diameter distributions were not significantly $(\mathrm{p}>0.05)$ different from the observed diameter distributions for $68 \%$ (CI $=95 \%$ ) and $80 \%$ (CI $=99 \%)$ of the observed Eucalyptus hybrid clone diameter distributions (Table 5). The scale parameter increased, and the shape parameter decreased, with increasing age and site class for both clones (Figure 2). For a similar stand age, clone A had lower scale and shape parameters than clone B. In addition, clone B had smaller variation in scale parameter but higher variation in shape parameter than clone A (Figure 2).

\section{Diameter distribution model comparisons}

Table 4 summarises the parameter estimates for fit data using maximum likelihood (MLE) and the three PRMs (MOM, PCT, and HYB). The results of the three PRMs indicated that all the three PRMs provided relatively similar mean parameter estimates for the Weibull distribution function, with the average scale parameter in the range of 9.53-10.37, and the average shape parameter in the range of 2.80-3.46. The MOM and HYB methods were more similar to the MLE based on the

TABLE 2: Parameter estimates and their associated standard errors (in parentheses), random effects standard deviations and goodness-of-fit statistics for arithmetic mean diameter and percentiles prediction models.

\begin{tabular}{clccc}
\hline Factor & Parameter & $\overline{\boldsymbol{D}}$ & $\boldsymbol{D}_{\mathbf{2 5}}$ & $\boldsymbol{D}_{\mathbf{9 9}}$ \\
\hline Fixed effects & $b_{0}$ & $3.7564(1.1495)$ & $1.2951(0.1785)$ & $1.9872(0.1591)$ \\
& $b_{1}$ & $1.5021(0.4841)$ & $0.0269(0.0088)$ & $-0.0155(0.0029)$ \\
& $b_{2}$ & $-0.7535(0.2975)$ & $0.0127(0.0036)$ & $0.0288(0.0012)$ \\
& $b_{3}$ & $15.3432(6.7380)$ & $0.6449(0.1969)$ & $-0.3663(0.3397)$
\end{tabular}

Random effects

\begin{tabular}{llllr} 
(Clone) & $\mathrm{s}\left(b_{0}\right)$ & 2.8489 & 0.2334 & 0.2135 \\
& $\mathrm{~s}\left(b_{1}\right)$ & 0.7263 & 0.0096 & $<0.0001$ \\
& $\mathrm{~s}\left(b_{2}\right)$ & 0.6312 & 0.0040 & 0.0001 \\
(Site Class / Clone) & $\mathrm{s}\left(b_{3}\right)$ & 13.2230 & 0.2348 & 0.1070 \\
& $\mathrm{~s}\left(b_{0}\right)$ & 2.8490 & 0.1454 & 0.0064 \\
& $\mathrm{~s}\left(b_{1}\right)$ & 1.1114 & 0.0129 & 0.0027 \\
Goodness-of-fit & $\mathrm{s}\left(b_{2}\right)$ & 0.7182 & 0.0050 & 0.1466 \\
Fixed & $\mathrm{s}\left(b_{3}\right)$ & 16.0999 & 0.2332 & 1.1510 \\
& & & & 0.8631 \\
Fixed +random & $\mathrm{rMSE}$ & 0.2874 & 1.1311 & 0.7320 \\
& $\mathrm{R}$ & 0.9821 & 0.5451 & 1.0592 \\
& $\mathrm{R}$ & -0.0829 & -0.5099 & 0.9327 \\
& $\mathrm{rMSE}$ & 0.2156 & 0.7953 & -0.0117 \\
\hline
\end{tabular}


TABLE 3: Coefficient estimates (fixed + random effects) of nonlinear mixed effect model by clone and site classes for arithmetic mean diameter and percentiles prediction models.

\begin{tabular}{clrrrrrrr}
\hline Equation & Parameter & \multicolumn{7}{c}{ Estimate coefficient by clone and site class } \\
& & A:22 & A:24 & A:26 & A:28 & B:24 & B:26 & B:28 \\
\hline \multirow{5}{*}{} & $b_{0}$ & 5.0580 & 6.8023 & 6.4207 & 5.9698 & 1.4566 & -0.6481 & 1.2354 \\
& $b_{1}$ & 0.1972 & 0.6093 & 0.3989 & 1.7608 & 2.7261 & 3.2856 & 2.0468 \\
& $b_{2}$ & -0.8457 & -1.5070 & -1.3428 & -1.6237 & -0.2855 & 0.2443 & -0.0292 \\
& $b_{3}$ & 2.6035 & 0.2958 & -0.3092 & 7.9372 & 31.4552 & 41.3175 & 27.9144 \\
\hline \multirow{2}{*}{$\boldsymbol{D}_{25}$} & $b_{0}$ & 0.9454 & 1.1477 & 1.2233 & 0.9345 & 1.4989 & 1.4012 & 1.6833 \\
& $b_{1}$ & 0.0070 & 0.0174 & 0.0041 & 0.0415 & 0.0351 & 0.0320 & 0.0421 \\
& $b_{2}$ & 0.0237 & 0.0155 & 0.0178 & 0.0096 & 0.0101 & 0.0125 & 0.0039 \\
& $b_{3}$ & 0.9622 & 0.8341 & 0.5222 & 1.1938 & 0.4514 & 0.5397 & 0.2436 \\
\hline \multirow{2}{*}{$\boldsymbol{D}_{99}$} & $b_{0}$ & 2.1217 & 2.1818 & 2.3095 & 2.3301 & 1.7646 & 1.7967 & 1.6186 \\
& $b_{1}$ & -0.0063 & -0.0224 & -0.0156 & -0.0165 & -0.0126 & -0.0115 & -0.0235 \\
& $b_{2}$ & 0.0289 & 0.0302 & 0.0269 & 0.0257 & 0.0285 & 0.0278 & 0.0333 \\
& $b_{3}$ & -0.7517 & -0.7901 & -1.0401 & -0.9254 & 0.1114 & 0.0389 & 0.3257 \\
\hline
\end{tabular}

average scale parameter, the PCT and HYB methods were relatively closer to the MLE based on the average shape parameter (Table 4; Figure 3). Shape parameters for HYB method were similar with the PCT that derived from the same variables and formulation (Table 4; Figure 3). Like most other applications, the shape parameter was more difficult to model than the scale parameter (Figure 3).

Based on the statistical model evaluation of three PRMs, the MOM had the best fit based on the KS statistic at 0.1757 , followed by the HYB and PCT with KS statistic at 0.1988 and 0.2125 , respectively (Table 5). The KS statistic also indicated the coverage (\# of observed distributions fitting within the 95\% CI) of estimated distributions were 49\% (MOM), 26\% (PCT), and 37\% (HYB); and 66\% (MOM), 44\% (PCT), and 54\% (HYB) at $99 \%$ confidence (Table 5). The MOM also had the lowest mean error-index at 26.5218, followed by HYB (27.7307) and PCT (31.4708) (Table 5). In terms of the differences in precision for predicting the Weibull parameter, the MOM has the lowest variability with the standard deviation of error index at 6.7118 and the PCT had the highest variability at 9.7699. Although all approaches allow for a direct mathematical link between the predicted overall stand characteristics and a diameter distribution that is

TABLE 4: Average of the parameter estimates of the Weibulll distribution using fit data and three prediction methods.

\begin{tabular}{lrrrrrrrr}
\hline \multirow{2}{*}{ Method } & \multicolumn{3}{c}{ Scale parameter $(\beta)$} & \multicolumn{4}{c}{ Shape parameter $(\gamma)$} \\
\cline { 2 - 9 } & Mean & Stdev & Min & Max & Mean & Stdev & Min & \multicolumn{1}{c}{ Max } \\
\hline MLE & 10.23 & 1.85 & 3.95 & 15.11 & 3.39 & 1.20 & 1.68 & 11.50 \\
MOM & 10.24 & 1.71 & 4.29 & 15.08 & 2.80 & 0.78 & 1.89 & 14.02 \\
PCT & 9.53 & 1.59 & 5.10 & 14.58 & 3.46 & 0.97 & 2.35 & 7.98 \\
HYB & 10.37 & 1.79 & 4.24 & 15.85 & 3.46 & 0.97 & 2.35 & 7.98 \\
\hline
\end{tabular}

TABLE 5: Means and standard deviations of the goodness-of-fit statistics produced by three diameter distribution prediction methods.

\begin{tabular}{cccccc}
\hline Method & \multicolumn{3}{c}{ KS } & \multicolumn{2}{c}{ EI } \\
\cline { 2 - 6 } & Mean & Stdev & Coverage (\%) & Mean & Stdev \\
\hline MLE & 0.1499 & 0.0699 & 68,80 & 23.6921 & 6.4569 \\
MOM & 0.1757 & 0.0724 & 49,66 & 26.5218 & 6.7118 \\
PCT & 0.2125 & 0.0759 & 26,44 & 31.4708 & 9.7966 \\
HYB & 0.1988 & 0.0825 & 37,54 & 27.7307 & 8.1979 \\
\hline
\end{tabular}

a Percentage of distributions that fall within $95 \%$ or $99 \%$ confidence intervals of the KS $\mathrm{D}_{\max }$ 

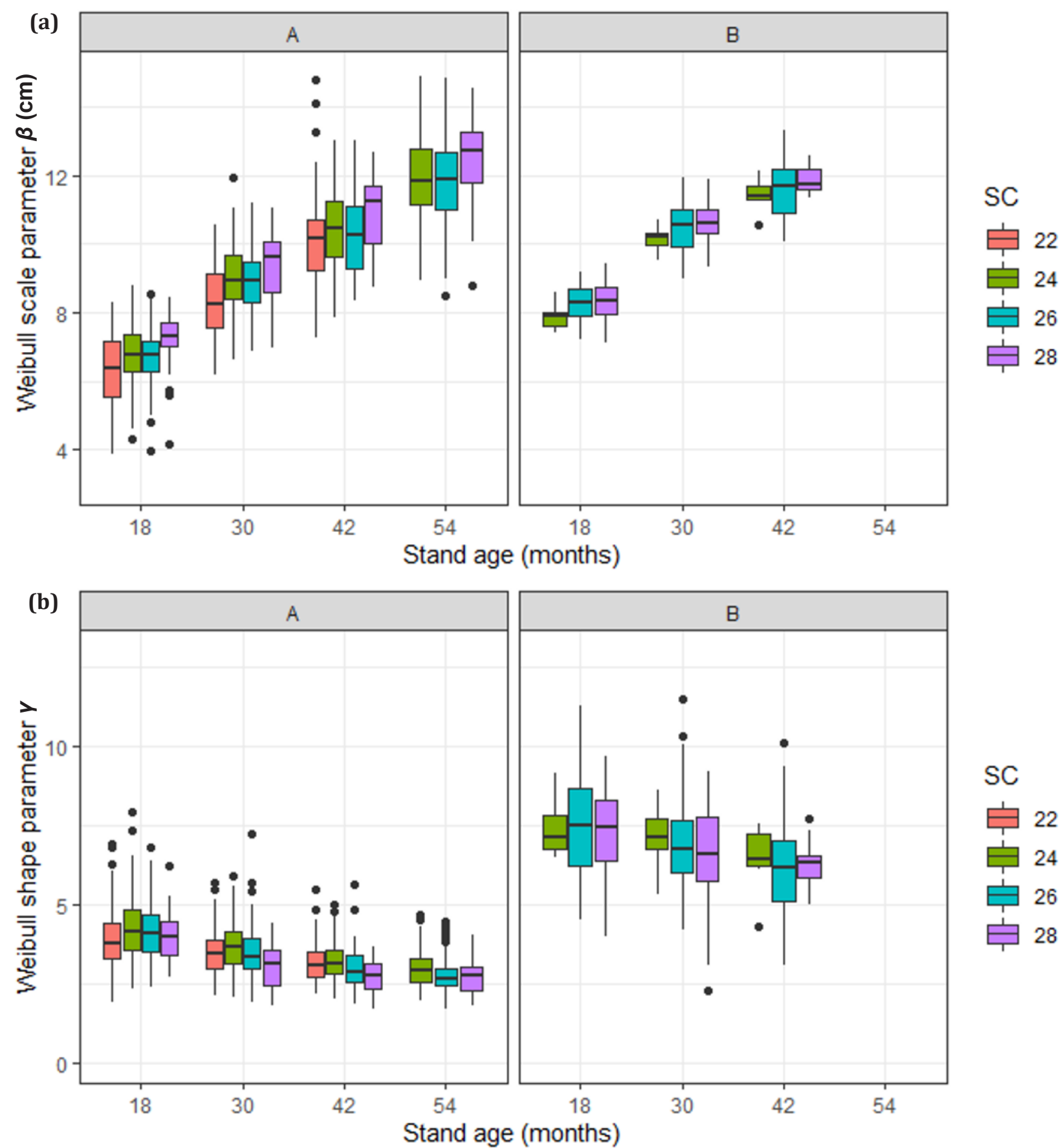

FIGURE 2: Boxplots of: Weibull scale $\beta$ (a); and shape $\gamma$ (b) parameter by clone, age and site class estimated from full sample of the trees in the plot using maximum likelihood estimation method. (A = clone "A"; B = clone "B"; $\mathrm{SC}=$ Site Class; the black dots indicate extreme values).

consistent with those characteristics, the moment-based method (MOM) indicated the best fit to the observed data when compared to the other methods (PCT and HYB).

For evaluation, some graphical examination of the performance of the three PRMs were conducted. Figure 4 illustrates the three methods for typical plots of the diameter distributions observed in the Eucalyptus hybrid clone plantations. The plots represent a range of clones, stand ages, and the variation of distributions typically observed in the region. Figure $4 \mathrm{a}$ shows a unimodal distribution for clone $\mathrm{A}$ at 30 months and illustrates that the three methods perform equally well for modeling the distribution of that plot. Figure $4 \mathrm{~b}$ shows a multimodal distribution. In this case, none of the three methods fitted the plot well and all missed the valley $(8-9 \mathrm{~cm})$ and the peak (13-14 cm). However, the MOM and PCT were better fits for the peak $(6-7 \mathrm{~cm})$ than the HYB. In Figure $4 \mathrm{c}$ for clone $\mathrm{B}$ at 30 months with a distribution that was close to normal, the MOM was the better fit than the others. The PCT and HYB show a similar pattern for this plot. While in Figure 4d with an irregular distribution, the MOM tends to deal with tails of both sides and MOM exhibited slightly greater flexibility in describing the larger variance than the two other methods. 

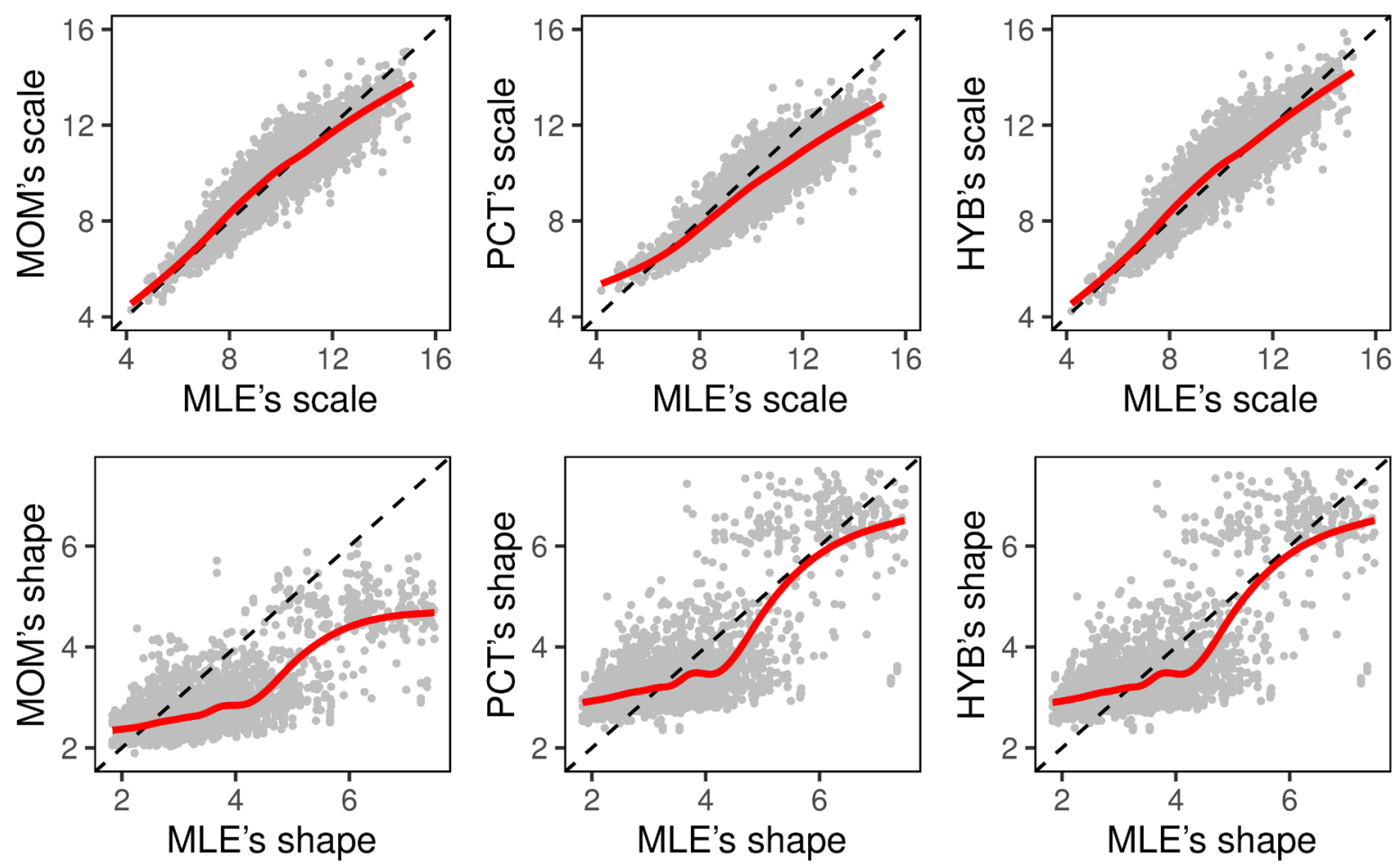

FIGURE 3: Parameter estimation comparison between MLEs and three parameter recovery estimation methods for scale (a; above) and shape (b; below). The dotted line represents the 1:1 line, while the red line is the observed trend using a smoothing line.

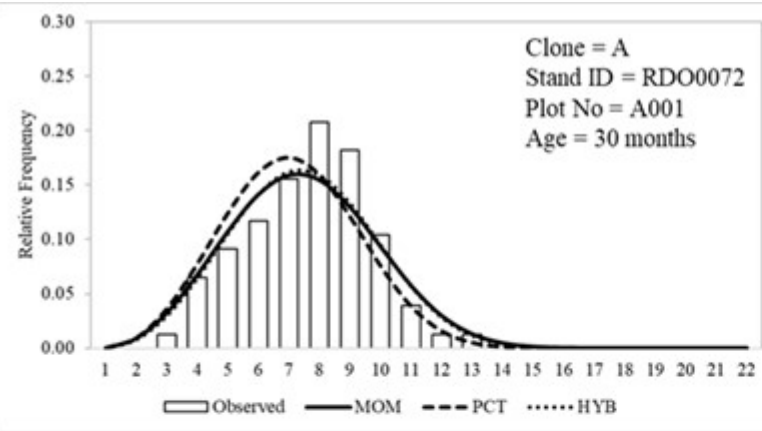

(a)

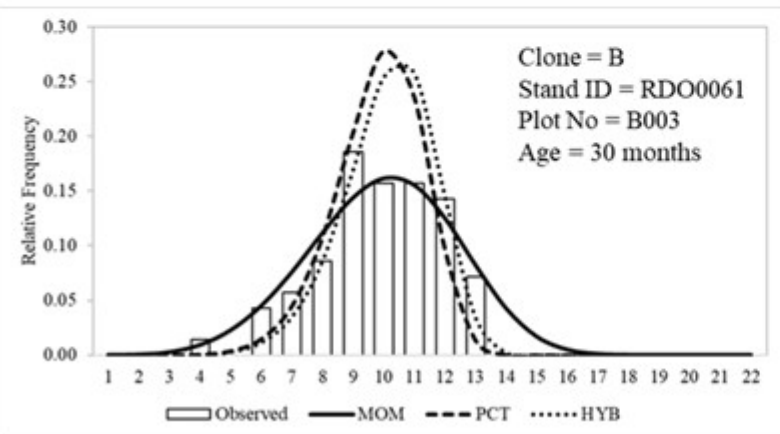

(c)

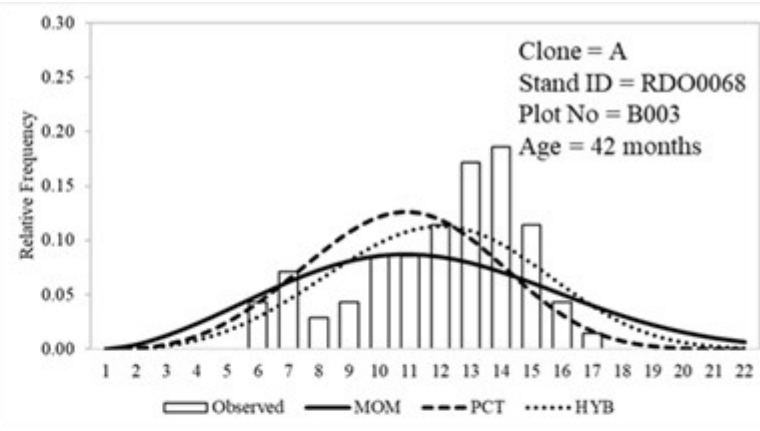

(b)

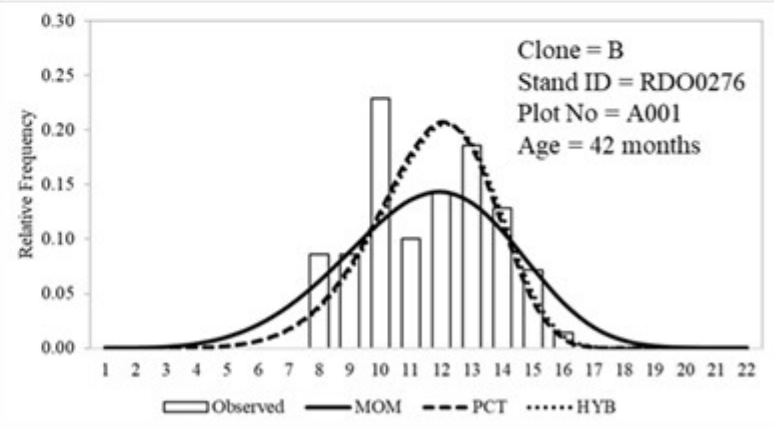

(d)

FIGURE 4: Model evaluation for the four example plots that represent: (a) clone A, 30 months; (b) clone A, 42 months; (c) clone B, 30 months; and (d) clone B, 42 months. The histogram represents the observed diameter distribution, and three curves represent diameter distribution models prediction. 


\section{Discussion}

To be compatible with a recently developed standlevel growth and yield model (Waldy et al. 2021), the predicted quadratic mean diameter played an important role in recovering parameters of the Weibull distribution that characterised the future diameter distributions. In this study, the prediction models were quite good at predicting arithmetic mean diameter and $99^{\text {th }}$ percentiles but relatively poor at predicting the $25^{\text {th }}$ percentile. This means that stand attributes, especially DQ and AGE, have a stronger correlation with the arithmetic mean diameter and higher percentiles than lower percentiles, which has been found in similar analyses. For example, Cao (2012) found similar trends in predicting future diameter distributions of loblolly pine (Pinus taeda L.). He found that stand attributes explained more variability in estimating higher percentiles $\left(50^{\text {th }}\right.$ percentile and above) than lower percentiles.

The method of moments is one of the most accurate methods for estimating the Weibull distribution parameters (Al-Fawzan 2000; Nanang 1998; Ueno \& Osawa 1987; Shifley \& Lentz 1985). Moments are the preferred method in growth and yield models because they ensure numeric compatibility and generally require fewer equations (Weiskittel et al. 2011). Our study indicated the MOM had a higher percentage of coverage for estimated distributions that fit the observed diameter distributions than PCT and HYB. This higher percentage for MOM in this study was likely because of sufficient sample sizes to model moment based recovery
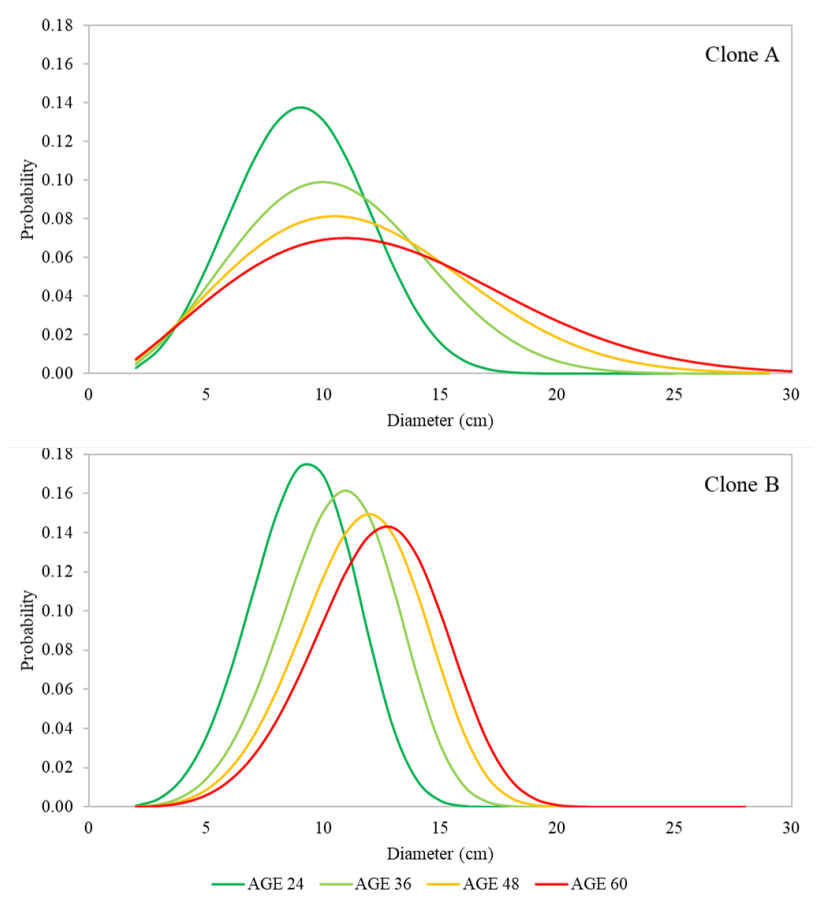

FIGURE 5: Simulated development of diameter distribution over ages using MOM method. Simulations are based on prediction standlevel variables (SD, BA, HT, RD and DQ) using site class $=26$ and initial stand density 1667 trees ha-1. with an average of 60 trees per plot (plot size $0.04 \mathrm{ha}$ ). Bankston (2019) reported that larger plot sizes resulted in more accurately predicted diameter distributions. However, he suggested a plot size of 0.08 ha might be sufficient for model building for data from unthinned stands. A substantial decrease in error was no longer evident when plot size increased from 0.08 to 0.10 hectares. Shiver (1988) suggested a sample size of not less than 50 trees is required to obtain satisfactorily accurate estimates of the Weibull parameters, while simulation studies from Saborowski (1994) indicated that a sample with $n=80$ could generally be expected to produce satisfactory results. To get a better diameter distribution that represented plot-level measurements, modifying the plot size is not a logical decision for the well-established forest inventory system applied by the APRIL group. Instead of using Weibull distributions, other probability density functions (e.g., beta, Johnson's SB, gamma or lognormal) are potentially worth examining to describe the structure of a Eucalyptus hybrid clone in this region. Goodwin (2020) suggested several variants of the Weibull distribution. While some of those models produced better estimates of diameter distributions, Goodwin's recommendation for plantations was to use the 3-P Weibull distribution, as done in this study.

Using simulated development of the MOM model predictions, the peakedness of the distribution was reduced for both clones with increasing stand age. The diameter distribution of clone A tended to become more positively skewed and the variation increased with increasing stand age (Figure 5), partly because of mortality in the lower tree strata, and thinnings from below, which remove the suppressed trees or crown thinning (thinning from above), which remove dominant and co-dominant trees (van Laar \& Akca 2007). The number of trees decreased in lower diameter classes and increased in upper classes, shifting curves to the right and increasing the flattening degree with increasing age. In clone B, the shape curves for all ages were almost similar with no significant increases in variation. These findings were relatively logical because the mortality for this clone was very low, so the diameter growth tends to be relatively uniform.

\section{Conclusions}

In this study, the moment method was found to give the lowest mean error-index and KS statistic, followed by the hybrid and percentile methods. Although all three methods had difficulty in describing multimodal diameter distributions, the moment method tended to be more robust with tails on both sides of the distribution and exhibited slightly greater flexibility in describing the larger variance than the two other methods. Overall, the Weibull approach appeared relatively robust in estimating diameter distributions of Eucalyptus hybrid clone plantation in Indonesia yet some refinements may be necessary to characterise more complex distributions and longer rotations. 


\author{
List of abbreviations \\ CDF Cumulative Distribution Function \\ dbh diameter at breast height \\ EI Error Index \\ HYB Hybrid \\ KS Kolmogorov-Smirnov \\ MLE Maximum Likelihood Estimation \\ MOM Moment \\ PCT Percentile \\ PDF Probability Density Function \\ PPM Parameter Prediction Method \\ PRM Parameter Recovery Method
}

\section{Competing interests}

The authors declare that they have no competing interests.

\section{Authors' contributions}

JW was the primary author, completed the statistical analyses and writing the manuscript draft. JAK contributed to the idea, review and editing the manuscript. AW and MD contributed to review and editing the manuscript. All authors read and approved the final manuscript.

\section{Acknowledgements}

The authors are grateful to PT. Riau Andalan Pulp and Paper, a member of APRIL Group that provided forest inventory data for this study.

\section{References}

Al-Fawzan, M.A. (2000). Methods for estimating the parameters of the Weibull distribution. InterStat, Statistics on the Internet.

Bailey, R.L., \& Dell, T.R. (1973). Quantifying diameter distributions with the Weibull function. Forest Sciences, 19(2), 97-104.

Bailey, R.L., Burgan, T.M., \& Jokela, E.J. (1989). Fertilized mid-rotation-aged slash pine plantations-stand structure and yield prediction models. Southern Journal of Applied Forestry, 13(2), 76-80. https:// doi.org/10.1093/sjaf/13.2.76

Baldwin, V.C., Jr., \& Feduccia, D.P. (1987). Loblolly pine growth and yield prediction for managed West Gulf plantations. [Res. Pap. SO-236] (27 p.). New Orleans, LA: U.S. Department of Agriculture, Forest Service, Southern Forest Experiment Station. https://doi.org/10.2737/SO-RP-236

Bankston, S. (2019). Sample-plot size and diameter moments/percentiles prediction model effects on stand diameter distribution recovery accuracy. Thesis. Department of Forestry, Mississippi State University.
Bolker, B.M. (2008). Ecological models and data in R. 1st ed. Princeton, NJ, USA: Princeton University Press. $396 \mathrm{p}$.

Borders, B.E., Souter, R.A., Bailey, R.L., \& Ware, K.D. (1987). Percentile-based distributions characterize forest stand tables. Forest Science, 33(2), 570-576.

Bowling, E.H., Burkhart, H.E., Burk, T.E., \& Beck, D.E. (1989). A stand-level multispecies growth model for Appalachian hardwoods. Canadian Journal of Forest Research, 19(4), 405-412. https://doi. org/10.1139/x89-064

Brooks, J.R., Borders, B.E., \& Bailey, R.L. (1992). Predicting diameter distributions for site-prepared loblolly and slash pine plantations. Southern Journal of Applied Forestry, 6(3), 130-133. https://doi. org/10.1093/sjaf/16.3.130

Burkhart, H.E., \& Tomé, M. (2012). Modelling forest trees and stands. Dordrecht, New York: Springer. https://doi.org/10.1007/978-90-481-3170-9

Bury, K. (1999). Statistical Distributions in Engineering. Cambridge: Cambridge University Press. https:// doi.org/10.1017/CB09781139175081

Cao, Q.V. (2004). Predicting parameters of a Weibull function for modelling diameter distribution. Forest Science, 50(5), 682-685.

Cao, Q.V. (2012). Use of the Weibull function to predict future diameter distributions from current plot data. In J.R. Butnor (Ed.), Proceedings of the 16th biennial southern silvicultural research conference. [e-General Technical Report SRS-156]. (pp. 53-58). Asheville, NC, USA: US Department of Agriculture Forest Service, Southern Research Station.

Cao, Q.V., \& McCarty, S.M. (2006). New methods for estimating parameters of Weibull functions to characterize future diameter distributions in forest stands. In K.F. Connor (Ed.), Proceedings of the 13th biennial southern silvicultural research conference. [e-Gen. Tech. Rep. SRS-92]. (pp. 338-340). Asheville, NC: U.S. Department of Agriculture, Forest Service, Southern Research Station.

Casella, G., \& Berger, R.L. (2001). Statistical inference, 2nd ed. Duxbury-Thomson Learning, 660 p.

Clutter, J.L., Fortson, J.C., Pienaar, L.V., Brister, G.H., \& Bailey, R.L. (1983). Timber management: A quantitative approach. John Wiley \& Sons, Inc. 333 p.

Clutter, J.L., Harms, R.W., Brister, G.H., \& Rheney, J.W. (1984). Stand structure and yields of site-prepared loblolly pine plantations in the lower coastal plain of the Carolinas, Georgia, and north Florida. [e-Gen. Tech. Rep. SE-27]. (173 p.). Asheville, NC: U.S. Department of Agriculture, Forest Service, Southeastern Forest Experiment Station. https:// doi.org/10.2737/SE-GTR-27 
Coble, D.W., \& Lee, Y.J. (2008). A new diameter distribution model for unmanaged slash pine plantations in east Texas. Southern Journal of Applied Forestry, 32(2), 89-94. https://doi.org/10.1093/sjaf/32.2.89

de Liocourt, F. (1898). De l'amenagement des sapinieres. [Bulletin Trimestriel Vol. 4]. (pp. 396-409). Societe Forestiere de Franche-Comte et Belfort.

De Miguel, E.P., Machado, S.A., Figueiredo Filho, A., \& Arce, J.E. (2010). Using the Weibull function for prognosis of yield by diameter class in Eucalyptus europhylla stands. Cerne, 16(1), 94-104. https:// doi.org/10.1590/S0104-77602010000100011

Dell, T.R., Fedducia, D.P., Campbell, T.E., Mann, W.F. Jr., \& Polmer, B.H. (1979). Yields of un-thinned slash pine plantations on cutover sites in the west Gulf region. [Res. Pap. SO-148]. (94 p.). New Orleans, LA: U.S. Department of Agriculture, Forest Service, Southern Forest Experiment Station.

Eisfeld, R.L., Sanquetta, C.R., Arce, J.E., Maestri, R., \& Weber, K.S. (2005). Growth and yield modelling of Pinus taeda L. using probability function. Floresta, 35(2), 317-328. https://doi.org/10.5380/ $\underline{\text { rf.v35i2.4619 }}$

Eslami, A.R., Karimi, B., Payam, H., \& Derakhshan, O.K. (2011). Investigation of the structure and distribution diameter classes models in beech forests of northern Iran. African Journal of Agricultural Research, 6(10), 2157-2165.

Feduccia, D.P., Dell, T.R., Mann, W.F. Jr., Campbell, T.E., \& Polmer, B.H. (1979). Yields of un-thinned loblolly pine plantations on cutover sites in the west Gulf region. [Res. Pap. SO-148] (94 p.). New Orleans, LA: U.S. Department of Agriculture, Forest Service, Southern Forest Experiment Station.

Goodwin, A.N. (2020). A blind spot in the use of the Weibull function for modeling diameter distributions. Forest Science, 67(2), 125-134. https://doi.org/10.1093/forsci/fxaa042

Hyink, D.M., \& Moser, J.W. (1983). A generalized framework for projecting forest yield and stand structure using diameter distributions. Forest Science, 29(1), 85-95.

Jiang, L., \& Brooks, J. R. (2009). Predicting diameter distributions for young longleaf pine plantations in Southwest Georgia. Southern Journal of Applied Forestry, 33(1), 25-28 https://doi.org/10.1093/ sjaf/33.1.25

Johnson, N.L., Kotz, S., \& Balakrishnan, N. (1995). Continuous univariate distributions, 2 nd ed. Wiley. $756 \mathrm{p}$.

Kershaw, J.A., Jr., Ducey, M.J., Beers, T.W., \& Husch, B. (2016). Forest Mensuration, 5th ed. Wiley/Blackwell, Hobokin, NJ. https://doi. org/10.1002/9781118902028
Kershaw, J.A., Jr., \& Maguire, D.A. (1995). Crown structure in western hemlock, Douglas-fir, and grand fir in western Washington: trends in branch-level mass and leaf area. Canadian Journal of Forest Research, 25(12), 1897-1912. https://doi.org/10.1139/x95$\underline{206}$

Kilkki, P., \& Paivinen, R. (1986). Weibull function in the estimation of the basal area dbh-distribution. Silva Fennica, 20(2), 149-156. https://doi. org/10.14214/sf.a15449

Kilkki, P., Maltamo, M., Mykkanen, R., \& Paivinen, R. (1989). Use of the Weibull function in estimating the basal area dbh-distribution. Silva Fennica, 23(4), 311-318. https://doi.org/10.14214/ sf.a15550

Knowe, S.A. (1992). Basal area and diameter distribution models for loblolly pine plantations with hardwood competition in the piedmont and upper coastal plain. Southern Journal of Applied Forestry, 16(2), 93-98. https://doi.org/10.1093/sjaf/16.2.93

Knowe, S.A., Foster, G.S., Roussau, R.J., \& Nance, W.L. (1994). Eastern cottonwood clonal mixing study: predicted diameter distributions. Canadian Journal of Forest Research, 24(2), 405-414. https://doi. org/10.1139/x94-054

Knowe, S.A., Harrington, T.B., \& Shula, R.G. (1992). Incorporating the effects of interspecific competition and vegetation management treatments in diameter distribution models for Douglas-fir saplings. Canadian Journal of Forest Research, 22(9), 1255-1262. https://doi. org/10.1139/x92-167

Knowe, S.A., Radosevich, S.R., \& Shula, R.G. (2005). Basal area and diameter distribution prediction equations for young Douglas-fir plantations with hardwood competition: coast ranges. Western Journal of Applied Forestry, 20(2), 73-93. https:// doi.org/10.1093/wjaf/20.2.77

Knowe, S.A., \& Stein, W.I. (1995). Predicting the effects of site preparation and protection on development of young Douglas-fir plantations. Canadian Journal of Forest Research, 25(9), 1538-1547. https://doi. org/10.1139/x95-167

Leduc, D.J., Matney, T.G., Belli, K.L., \& Baldwin, V.C., Jr. (2001). Predicting diameter distributions of longleaf pine plantations: a comparison between artificial neural networks and other accepted methodologies. [Res. Pap. SRS-25] (24 p.). Asheville, NC: U.S. Department of Agriculture, Forest Service, Southern Research Station. https:// doi.org/10.2737/SRS-RP-25

Lee, Y.J., \& Coble, D.W. (2006). A new diameter distribution model for unmanaged loblolly pine plantations in east Texas. Southern Journal of Applied Forestry, 30(1), 13-20. https://doi. org/10.1093/sjaf/30.1.13 
Lindsay, S.R., Wood, G.R, \& Woollons, R.C. (1996). Stand table modelling through the Weibull distribution and usage of skewness information. Forest Ecology and Management, 81(1-3), 19-23. https://doi. org/10.1016/0378-1127(95)03669-5

Little, S.N. (1983). Weibull diameter distributions for mixed stands of western conifers. Canadian Journal of Forest Research, 13(1), 85-88. https:// doi.org/10.1139/x83-012

Lohrey, R.E., \& Bailey, R.L. (1976). Yield tables and stand structure for un-thinned longleaf pine plantations in Louisiana and Texas. [Res. Pap. SO-133] (53 p). New Orleans, LA: U.S. Department of Agriculture, Forest Service, Southern Forest Experiment Station.

Magnussen, S. (1986). Diameter distributions in Picea abies described by the Weibull model. Scandinavian Journal of Forest Research, 1(1-4), 493-502. https:// doi.org/10.1080/02827588609382440

Massey, F.G.J.R. (1951). The Kolmogorov-Smirnov test for goodness of fit. Journal of the American Statistical Association, 46, 68-78. https://doi.org/10.1080/0 $\underline{1621459.1951 .10500769}$

Matney, T.G., \& Farrar, R.M. (1992). A thinned/un-thinned loblolly pine growth and yield simulator for planted cutover site-prepared land in the Mid-Gulf South. Southern Journal of Applied Forestry, 16(2), 70-75. https://doi.org/10.1093/sjaf/16.2.70

Matney, T.G., \& Sullivan, A.D. (1982). Compatible stand and stock tables for thinned and unthinned loblolly pine stands. Forest Science, 28(1), 161-171.

McTague, J.P., \& Bailey, R.L. (1987). Compatible basal area and diameter distribution models for thinned loblolly pine plantations in Santa Catarina, Brazil. Forest Science, 33(1), 43-51.

Nanang, D.M. (1998). Suitability of the Normal, Lognormal and Weibull distributions for fitting diameter distributions of neem plantations in Northern Ghana. Forest Ecology and Management, 103(1), 1-7 https://doi.org/10.1016/S03781127(97)00155-2

Newton, P.F., Lei, Y., \& Zhang, S.Y. (2004). A parameter recovery model for estimating black spruce diameter distribution within the context of a stand density management diagram. The Forestry Chronicle, 80(3), 349-358. https://doi. org/10.5558/tfc80349-3

Newton, P.F., Lei, Y., \& Zhang, S.Y. (2005). Stand-level diameter distribution yield model for black spruce plantations. Forest Ecology and Management, 209, 181-192. https://doi.org/10.1016/j. forec0.2005.01.020

Pinheiro, J.C., \& Bates, D.M. (2000). Mixed effects models in S and S-Plus. New York: Springer. 528 p. https:// doi.org/10.1007/978-1-4419-0318-1
Poudel, K.P., \& Cao, Q.V. (2013). Evaluation of methods to predict Weibull parameters for characterizing diameter distributions. Forest Science, 59(2), 243252. https://doi.org/10.5849/forsci.12-001

R Core Team. (2020). R: A Language and Environment for Statistical Computing. R Foundation for Statistical Computing. https://www.R-project.org/ (accessed on 14 Sept 2020).

Rennolls, K., Geary, D.N., \& Rollinson, T.J.D. (1985). Characterizing diameter distributions by the use of Weibull distribution. Forestry: An International Journal of Forest Research, 58(1), 57-66 https:// doi.org/10.1093/forestry/58.1.57

Reynolds, M.R., Burk, T.E., \& Huang, W.C.(1988). Goodness of-fit tests and model selection procedures for diameter distribution models. Forest Science, 34(2), 373-399.

Royle, J.A., \& Dorazio, R.M. (2008). Hierarchical modelling and inference in ecology: The analysis of data from populations, metapopulations and communities. San Diego, CA: Academic Press. 444 p

Saborowski, J. (1994). Minimum sample size for estimating the Weibull parameters of diameter distributions. Proceedings of IUFRO Symposium. Stellenbosch, pp 1-7

Schreuder, H.T., Hafley, W.L., \& Bennet, F.A. (1979). Yield prediction for un-thinned natural slash pine stands. Forest Science, 25(1), 25-30.

Schreuder, H.T., \& Swank, W.T. (1974). Coniferous stands characterized with the Weibull distribution. Canadian Journal of Forest Research, 4(4), 518-523. https://doi.org/10.1139/x74-075

Sghaier, T., Cañellas, I., Calama, R., \& Sánchez-González, M. (2016). Modelling diameter distribution of Tetraclinis articulata in Tunisia using normal and Weibull distributions with parameters depending on stand variables. iForest - Biogeosciences and Forestry, 9, 702 -709. https://doi.org/10.3832/ ifor1688-008

Shifley, S.R., \& Lentz E. (1985). Quick estimation of the three-parameter Weibull to describe tree size distributions. Forest Ecology and Management, 12, 195-203. https://doi.org/10.1016/03781127(85)90034-9

Shiver, R.D. (1988). Sample size and estimation methods for the Weibull distribution in un-thinned and thinned pine plantation diameter distributions. Forest Science, 24(3), 809-814.

Siipilehto, J. (1999). Improving the accuracy of predicted basal-area diameter distribution in advanced stands by determining stem number. Silva Fennica, 33(4), 281-301. https://doi.org/10.14214/sf.650

Siipilehto, J., \& Mehtätalo, L. (2013). Parameter recovery vs. parameter prediction for the Weibull distribution validated for Scots pine stands in 
Finland. Silva Fennica. 47(4), 1-22.

Smalley, G.W., \& Bailey, R.L. (1974a). Yield tables and stand structure for loblolly pine plantations in Tennessee, Alabama, and Georgia highlands. [Res. Pap. SO-96]. (81 p.). New Orleans, LA: U.S. Department of Agriculture, Forest Service, Southern Forest Experiment Station.

Smalley, G.W., \& Bailey, R.L. (1974b). Yield tables and stand structure for shortleaf pine plantations in Tennessee, Alabama, and Georgia highlands. [Res. Pap. S0-97]. (57 p.). New Orleans, LA: U.S. Department of Agriculture, Forest Service, Southern Forest Experiment Station.

Strub, M.R., \& Burkhart, H.E. (1975). A class-intervalfree method for obtaining expected yields from diameter distributions. Forest Science, 21(1), 6769.

Ueno, Y., \& Osawa, Y. (1987). The applicability of the Weibull and the expanded Weibull distributions. Journal of the Japanese Forest Society, 69(1), 24-28.

van Laar, A., \& Akça, A. (2007). Forest Mensuration. 2nd edition. New York: Springer https://doi. org/10.1007/978-1-4020-5991-9

Vanclay, J.K. (1994). Modelling forest growth and yield: applications to mixed tropical forests. $\mathrm{CAB}$ International.

Waldy, J., Kershaw, J.A., Jr., Weiskittel, A., \& Ducey, M.J. 2021. Comparison of time-based versus statespace stand growth models for tropical hybrid Eucalyptus clonal plantations in Sumatera, Indonesia. Canadian Journal of Forest Research, 51(8), 1178-1187 https://doi.org/10.1139/cjfr2020-0499

Weiskittel, A.R., Hann, D.W., Kershaw, J.A., \& Vanclay, J.K. (2011). Forest growth and yield modeling. Hoboken, NJ: Wiley. https://doi. org/10.1002/9781119998518

Zarnoch, S.J., \& Dell, T.R. (1985). An evaluation of percentile and maximum likelihood estimators of Weibull parameters. Forest Science, 31(1), 260268.

Zarnoch, S.J., Feduccia, D.P., Baldwin, V.C., Jr., \& Dell, T.R. (1991). Growth and yield predictions for thinned and un-thinned slash pine plantations on cutover sites in the West Gulf region. [Res. Pap. SO-264]. (32 p.). New Orleans, LA, USA: US Department of Agriculture, Forest Service, Southern Forest Experiment Station. https://doi.org/10.2737/SO$\underline{\mathrm{RP}-264}$ 